\title{
On the Economics of Plagiarism
}

\author{
Alan Collins*, Guy Judge*, Neil Rickman ${ }^{* *}$ \\ Department of Economics, University of Portsmouth \\ ${ }^{* * *}$ Department of Economics, University of Surrey
}

\section{Correspondence Address:}

Prof. Alan Collins

Department of Economics

University of Portsmouth

Richmond Building, Portland Street,

Portsmouth, PO1 3DE. U.K.

Tel: $++44(0) 2392844128$

Fax: ++44(0)239284 4037

Email: alan.collins@port.ac.uk 


\section{On the Economics of Plagiarism ${ }^{1}$}

Abstract: Cheating and plagiarism can involve the transgression of intellectual property rights across many areas of life. When a direct financial benefit from such practices is identifiable, the opportunity to seek legal redress is available via civil court action. When it is undertaken by a public official it may constitute malfeasance. Yet in the case of breaches of university regulations (from the growing number of student cheating and plagiarism incidents) subsequent legal intervention may be characterised by situations where the university is the defendant and the alleged plagiarist is the plaintiff (seeking compensation for interrupted study and/or tarnished reputation). University defences can flounder around the issue of proving intent to deceive. What can they do to try to prevent such occurrences? This paper uses economic analysis to examine such issues. Economic models of plagiarism motivated primarily by (i) time-saving and (ii) dishonesty are developed to help frame the discussion. Both model approaches overlap in their implications, namely, ensuring that sufficient resources are devoted to monitoring coursework (to increase the probability that cheating and plagiarism are detected) and of providing sufficiently clear and severe institutional penalties (to counter-balance any expected benefits that the student may perceive to be available from cheating and plagiarism). Policy proposals are raised for further debate and consideration.

JEL codes: I21, H42, K42.

Keywords: plagiarism, cheating, deception, Higher Education.

\footnotetext{
${ }^{1}$ We are grateful to an anonymous referee for his critical but constructive comments on an earlier draft of this paper. In addressing these points we believe that our argument has been significantly strengthened.
} 


\section{$\underline{\text { INTRODUCTION }}$}

Cheating and plagiarism can involve the transgression of intellectual property rights across many areas of life. A recent high profile example is the case of Acquaviva v Madonna reported in BBC (2005). In that instance a Belgian songwriter (Salvatore Acquaviva) won a court battle against pop star Madonna after accusing her of plagiarising one of his songs for her 1998 hit single, "Frozen". Another case relates to an instance of plagiarism by staff at the UK Government Foreign and Commonwealth Office in a report relating to the potential terrorism risks posed by the former Iraqi regime (Rangwala, 2003). There have also been cases of journalists who have had to resign after being found guilty of plagiarism (Byrne, 2003). Plagiarism among academic economic researchers has also been subject to detailed consideration (Enders and Hoover 2004).

When a direct financial benefit from such practices is identifiable, the opportunity to seek legal redress is available via civil court action. When it is undertaken by a public official it may constitute malfeasance. Yet in the case of breaches of university regulations (from the growing number of student cheating and plagiarism incidents) subsequent legal intervention, may actually be characterised by situations where the university is the defendant and the alleged plagiarist is the plaintiff (seeking compensation for interrupted study and/or tarnished reputation). See, for example, Clark versus University of Lincolnshire and Humberside (2000). The case shows the difficulties in proving intent to deceive.

The extent of plagiarism among students is now a growing concern within higher education institutions (HEIs) around the world (Larkham and Manns, 2002). In the academic community anecdotal evidence alongside formal and casual empiricism suggests that instances of plagiarism have increased significantly (Furedi 2004). A recent survey of UK university students found that 
about one quarter of them admitted to plagiarising and $16 \%$ said that that they had done so more than once (BBC 2004).

Plagiarism is also a problem in North America: McCabe (2003) found that $38 \%$ of students in the 23 US universities he sampled admitted to plagiarism (compared with only $10 \%$ in a similar but smaller survey conducted three years earlier).

In the UK an MBA student recently faced expulsion from her university after it was discovered that she had paid an essay writing company to produce coursework for her (Curtis 2003). Many universities now have substantial sections on their web pages warning students about plagiarism (for general advice see, for example, JISC 2005). Some make use of software services such as those offered by turnitin.com or the JISC Plagiarism Advisory Service to check a sample of submitted coursework for plagiarism (JISCPAS 2004).

The costs of such activity are potentially large. As well as damaging the integrity of degree awards in a global marketplace (and thus potentially leading to some measure of trade deflection), plagiarism diverts scarce academic resources away from research and teaching, towards monitoring and detection activities. Thus, there is significant (and timely) policy relevance, in addition to natural academic interest, in opening up economic debate on this theme. By directing some economic research attention to plagiarism in HEIs it may be possible to help explain its apparently increasing prevalence and better devise policies to combat this phenomenon.

An alternative view may be, however, that plagiarism and cheating have now become much more accepted behavioural norms (Szabo and Underwood, 2003), such that their presence carries through useful skills into work environments. This is not to say that deception practices being utilised by students is a new phenomenon. In his novel Porterhouse Blue Tom Sharpe (1974) details some past practices that featured in the days before student photo-identity cards. He presents a fictional 
account of the means by which students, who through an intermediary (Scullion), could employ a more academically gifted student to do coursework for them or sit their examinations. The fee for this service varied according to the desired class of examination/coursework mark. There are numerous other anecdotal tales of similar practices and educational corruption from around the world. Yet while such practices are not new it is the case that technical change (principally in terms of electronic library services and Internet search engines) and market evolution (the emergence of plagiarism or cheat service websites and firms) has made the practice of plagiarism significantly less time-intensive, cheaper and of more widespread availability.

It is contended herein that value may be added to the study and development of plagiarism and counter-plagiarism tactics and policies by the adoption of an economic approach. This paper articulates the rationale for this assertion and brings to bear some of the relevant conceptual tools for analysing this growing phenomenon. Drawing on such thinking, key policy implications are raised along with a series of empirical questions that beg to be addressed so that policy may be more fully informed by firmer evidence. Section I discusses the changing nature of Higher Education and the reasons why students may be motivated to plagiarise. Section II presents and analyses various economic models of plagiarising behaviour. Section III considers counterplagiarism policies in Higher Education. Section IV provides some concluding remarks and identifies some questions for future research.

\section{THE CHANGING NATURE OF HIGHER EDUCATION AND THE MOTIVATION TO PLAGIARISE}

\section{The Good Old Days?}

Prior to the widespread use of the Internet, plagiarism principally entailed physically assembling hard copies of sources to plagiarise from and then transcribing and integrating them into a coherent, hopefully seamless essay format. Since this method still requires the use of some significant 
analytical thought in order to synthesise a successful plagiarised essay, it may be that the incremental effort required to fashion the work into a non-plagiarised essay would not be great. In this way the state of technology could be argued to have inhibited the extent of plagiarism to some degree. Furthermore, university education prior to the widespread use of the Internet might also be reasonably described as characterised not only by much smaller student cohorts with more generous student grants, but also a much higher proportion of more academically motivated students. Such students would thus be less likely to perceive a need to resort to plagiarism and would be more likely to subscribe to the academic honour codes or social customs associated with their presence in the university community. Not only would the smaller student intakes make the expected probability of detection seem higher, as detection effort would clearly be spread among a lower number of students, but also the smaller cohorts would be more likely to socially interact and form social capital, such that academic honour codes and other customs associated with a sense of collegiality would more easily be reinforced.

\section{Changing academic honour codes?}

There is a growing body of work providing economic analyses of the extent to which individuals are willing to follow social customs such as academic honour codes. Such codes effectively form, in the terminology of Gifford (1999), a 'mental public good' that does not wear out with use but is actually strengthened by increasing use. Yet it is also diminished or destroyed by misuse or nonuse. Following Akerlof (1980) observance or otherwise of an academic honour code could be viewed in terms of the standard postulates of utility maximisation, where an individual is motivated by some implicit cost-benefit calculation. Therein Akerlof focuses on a possible prisoner's dilemma with two clearly sub-optimal scenarios. In the extreme cases, these are where the academic honour code is obeyed even though all agents (the students) are disadvantaged by so doing and the other where all agents, despite widespread welfare losses, do not obey the honour code.

Another factor that may well have contributed to changing attitudes among students is the increasing sense of university corporatism. By this we mean a process whereby academics are 
merely seen as employees and students are seen first and foremost as 'customers' purchasing a service/degree certificate which is subject to formal quality assurance procedures in a manner somewhat akin to purchases of any other goods, such as chocolate biscuits.

\section{Alternative motivations for plagiarism?}

For some individuals, participation in plagiarism may simply arise where deception behaviour is an intrinsic personality trait and thus a significant source of utility. However it is contended that much plagiarism can principally be explained in terms of a perceived need to save academic time (effort) in the face of competing uses of time: leisure and part-time work. Indeed the BBC story of the UK survey cited above reported that this was one of the two main reasons given by students for cheating. The time-saving nature of plagiarism-supporting innovations may thus be welcomed by a subset of those students who, for example, face severe income constraints and need to engage in significant amounts of part-time work to support their university education. The academic opportunity cost of such part-time work hours could thus be mitigated to some extent by recourse to time saving but deception-based academic practices. To capture this type of behaviour we develop a series of models based on the assumption that students are plagiarising in order to save time.

The dramatic growth of overseas student numbers (many with part-time work needs) has generated additional recruits to the likely pool of those who could more easily be tempted to engage in plagiarism. This is understandable given that the academic work hours needed to achieve a given level of educational attainment is necessarily increased for some students by the need also to engage in substantial language translation effort. There may also be generational and cross-cultural differences in the perception of plagiarism as wrongdoing. Another possibility is that students feel under pressure to obtain at least an Upper Second Class award on their degree courses so that they can proceed to Masters level courses or to compete effectively in the job market. Some students who feel that they are not able to guarantee marks at this level, no matter how much honest work that they do, may be tempted to plagiarise in order to overcome academic deficiencies. In any case 
the second reason given by students in the UK plagiarism survey was that they found it easier to cheat than to do the work themselves. Accordingly we develop a second type of model where cheating is a substitute for honest work in the 'marks production function'.

To conclude this section we argue that the decision to participate in plagiarism today is not principally influenced by the durability of social customs or academic honour codes. It should be thought of more in terms of an orthodox illegitimate activity that can readily be viewed in a framework that partially exploits the work of Becker $(1965,1968)$ as a starting point.

\section{ECONOMIC MODELS OF PLAGIARISING BEHAVIOUR}

Galles et al (2003) observe that the typical prescription to the problem of plagiarism is to step up monitoring efforts. They conclude this is both difficult and costly and accordingly advance the case for a preferred strategy. This consists of tougher and more consistent sanctions. In this paper, an attempt is made to address and frame the same problem in a way that more explicitly fleshes out the specific motivations for cheating and plagiarism activity in order to inform policy discussion at a somewhat finer scale of resolution.

As we have noted, students may be motivated to engage in plagiarism for a number of reasons. Perhaps the most important is simply to save time. Contemporary students may have to divide their time between three activities: study, leisure and part-time work. Stevens and Weale (2004) provide some figures on the average hours per week devoted to each of these activities from a survey of UK university students conducted in 2000 and 2001, and an analysis of how the part-time wage rate can affect the allocation of time between each activity. To the extent that students can save time by plagiarising they can keep study time in check and make more time for the other two activities. An alternative view is that students seek to improve the mark that they are awarded for their work and that they do this by attempting to pass off someone else's work as their own. Here we analyse 
various models that attempt to capture the essentials of these different types of behaviour.

\section{(a) Time saving plagiarism models}

\section{Case 1: Simple plagiarism by a student}

Assume that the student has a certain amount of time T available for leisure or for study. Let $\mathrm{s}$ be the amount of time devoted to study and $\mathrm{L}$ is the remaining leisure time. We assume that time devoted to study improves the student grade and hence contributes to utility. But we also assume that the student enjoys utility from leisure time. We can introduce a budget constraint as well as a time constraint and assume that the student works to supplement her income, which can be used to buy consumer goods and services.

The student is aware that there is a risk that they will be caught cheating. She therefore chooses her study hours, work hours, consumption of ordinary goods and services and expenditure on plagiarism so as to maximize expected utility, which must include the expected disutility that she will suffer if she is caught cheating.

Let $\mathrm{m}=$ exogenously provided income (grant, money from parents etc.)

Let $\mathrm{h}=$ number of hours worked part-time

Let $\mathrm{w}=$ the hourly wage rate

Let $\mathrm{x}=$ amount of consumer goods purchased

Let $\mathrm{p}=$ price of consumer goods

Let $\mathrm{c}=$ cost of one item of plagiarised material.

Let $\mathrm{q}=$ the number of items of plagiarised materials that the student purchases.

Let $\mathrm{f}=$ the time freed up by each unit of plagiarism.

Let $r=$ the risk (probability) of the student plagiarist being caught (detected).

Let $\mathrm{K}(\mathrm{q})=$ the disutility or cost of being caught plagiarising. This could be via a punishment such as the reduction of a degree award or the need to resubmit work with a capped mark, or even the anticipated loss of future earnings due to less favourable references etc. It is assumed that this cost 
increases with the number of items that the student has been caught plagiarising - here we assume that if a student is caught plagiarising once she will be fully investigated so that all other instances of plagiarism will be identified.

The formal model may be stated as follows:

For this problem the Lagrangian is

In this model the student must choose how much time to spend studying (s), how much time to spend on paid employment (h), how much of her budget to spend on ordinary goods and services (x) and how much to spend on plagiarised material (q). The necessary conditions for maximising expected utility subject to the time and budget constraints are ${ }^{2}$ :
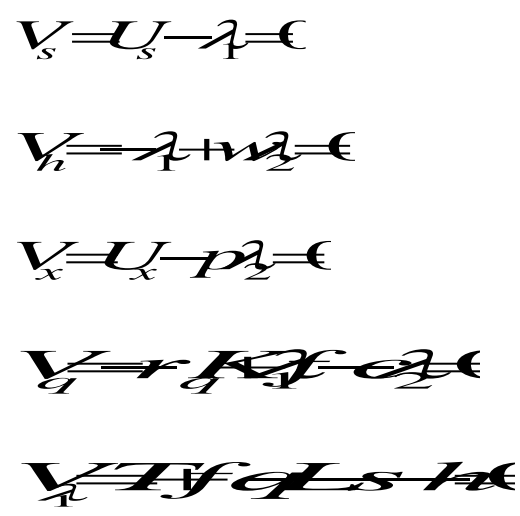

Solving equations [1.1] to [1.4] yields the following condition

$$
\frac{U_{x}}{p}=\frac{U_{s} f-r K_{q}}{c}
$$

If we first assume that the risk of being caught plagiarizing is zero (or that, at the margin, there is no disutility suffered from being caught plagiarizing) then this would reduce to

\footnotetext{
${ }^{2}$ In this model the consumption of plagiarised material does not contribute directly to utility, However it can free up time that can then either be spent on study, or in paid employment which can augment income and thus allow for
} 
$\frac{U_{x}}{p}=\frac{U_{s}}{c} f \quad$ which could also be written as $\frac{U_{x}}{f U_{s}}=\frac{p}{c}$

The student would consume a combination of normal goods and plagiarised material up to the point where the ratio of the cost of these items is equated with the ratio of the marginal utility of consuming normal goods to the marginal utility derived from an additional unit of study, weighted by the extra amount of time freed up by purchasing an extra unit of plagiarised material.

However, interpreting the full condition given in [1.7], when there is some chance of the student being caught plagiarizing this will bring down the expected benefits of the time saved - the more so the larger is the marginal disutility suffered when being caught plagiarizing.

Rearranging equation [1.5], substituting into [1.7] and solving for q we find

$$
\begin{aligned}
& \frac{c}{p} U_{x}+r K_{q}=U_{S}\left(\frac{L+s+h-T}{q}\right) \text { giving } \\
& {[1.8] \quad q=\frac{U_{S}(L+s+h-T)}{\frac{c}{p} U_{x}+r K_{q}}}
\end{aligned}
$$

So, again first considering the situation of no risk of being caught, we find

$$
q=\frac{U_{S}(L+s+h-T)}{\frac{c}{p} U_{x}}
$$

But the introduction of a risk of apprehension, or a significant punishment for being caught cheating, will lower the amount of plagiarism undertaken since the denominator in [1.8] is that much larger than in [1.9]

Case 2: The student engages in two forms of plagiarism with different costs, time saved and risks of being caught. 
Plagiarism can take a variety of forms. Here we distinguish two types. Type 1 plagiarism is where the student constructs their assessed work from a variety of publicly available (free) sources. These could take the form of online materials that have been downloaded and cut and pasted into the submitted work, or they could be taken from printed material that is in the public domain. Although this material is free there is a small cost to the student in assembling the material. However provided that they are not caught this cost is outweighed by the time freed up by this form of cheating. Even if they are caught it might be worth taking the risk if the probability of detection and the penalty are not too high.

Type 2 plagiarism is where the student pays privately for someone else to do the work, either mediated by an online cheat site, or through some other private arrangement (say paying a fellow student to do the work).

So let $\mathrm{q}_{1}$ denote the quantity of type 1 plagiarised material

let $\quad c_{1}$ denote the cost of creating one unit of this type of material

let $\mathrm{f}_{1}$ denote the time freed up by this form of plagiarism

let $\quad r_{1}$ denote the risk of being detected engaging in this form of plagiarism

let $\quad \mathrm{q}_{2}$ denote the quantity of type 2 plagiarised material purchased

let $\quad c_{2}$ denote the cost of purchasing one unit of this type of material

let $\mathrm{f}_{2}$ denote the time freed up by this form of plagiarism

let $\quad r_{2}$ denote the risk of being detected engaging in this form of plagiarism

So the problem becomes

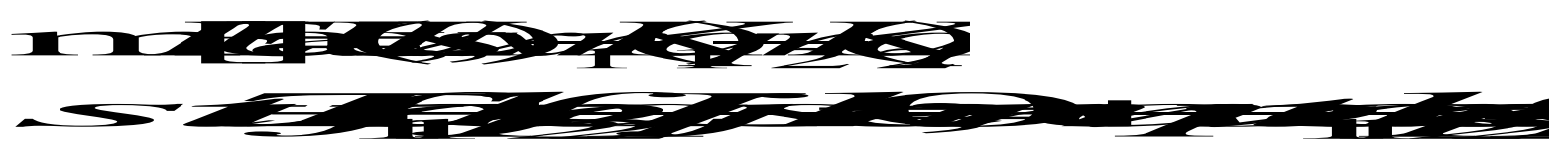

and the Lagrangian becomes 
The student must choose $\mathrm{s}, \mathrm{h}, \mathrm{x}$ and $\mathrm{q}_{1}$ and $\mathrm{q}_{2}$ and the necessary conditions for maximising expected utility subject to the time and budget constraints are:

$$
V=C
$$

$$
K=7+2=\epsilon
$$
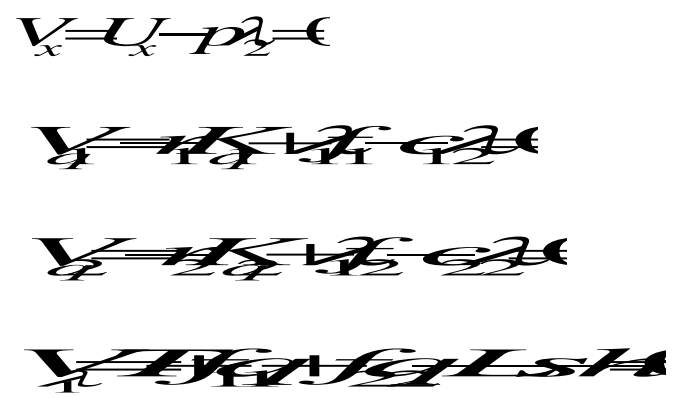

But now $\lambda_{2}=\frac{U_{x}}{p}=\frac{\lambda_{1} f_{1}-r_{1} K_{q 1}}{c_{1}}=\frac{\lambda_{1} f_{2}-r_{2} K_{q 2}}{c_{2}}$

Substituting for $\lambda_{1}$ and rearranging we find

$$
\frac{U_{x}}{p}=\frac{U_{s} f_{1}-r_{1} K_{q 1}}{c_{1}}=\frac{U_{s} f_{2}-r_{2} K_{q 2}}{c_{2}}
$$

As before if we first consider a case where there is no risk of being caught plagiarizing, then students will arrange matters such that

[2.9] $\frac{U_{x}}{p}=\frac{U_{S} f_{1}}{c_{1}}-\frac{U_{S} f_{2}}{c_{2}}$ 
It is likely that $c_{1}<c_{2}$ (privately paid for plagiarised material will cost more than material taken from public sources) and we also expect $\mathrm{f}_{1}<\mathrm{f}_{2}$ (downloaded material will take more time to put together than purchased material), so these factors may tend to offset each other leading to timesaving students making use of both types of plagiarised work. Interpreting the full condition [2.9] we expect $r_{2}<r_{1}$ (privately plagiarised material will be harder to detect than material taken from public sources which can usually be tracked down via web searches or using tools such as turnitin.com or with help from the JISC Plagiarism Advisory Service (JISCPAS 2004)). Probably the university authorities would take stronger action against students who indulge in the more blatant type 2 form of cheating so we expect $\mathrm{K}_{\mathrm{q} 2}>\mathrm{K}_{\mathrm{q} 1}$. Thus while the risk of being caught may be lower, the anticipated punishment would be greater and so these two factors may also tend to offset each other. For these reasons we cannot say outright whether more of one type of plagiarism will be consumed than the other; it depends not only on the costs of plagiarism but also the risks of being caught, the expected scale of punishment and the relation of all of these factors to the marginal utility of study time. However increasing both the risk of being apprehended and the punishment for plagiarism would reduce the amount of either type of plagiarism.

\section{(b) A mark enhancement model}

Here we focus on students who plagiarise in order to improve their mark or grade, rather than to save time. The student may choose two inputs to produce marks $(Y)$ : honest work $(W)$ and cheating $(C)$.

The 'marks production function' $Y(W, C)$ is well-behaved with positive but diminishing marginal products. If cheating occurs, let the probability of its detection be $p(C) \in[0,1]$, with $p^{\prime}(C)>0, p(0)=0$. If the student is caught cheating, she incurs a penalty of $\mathrm{Z}<0$. Both types of effort are costly to the student: $\psi(W, C)$, which is increasing and convex in both arguments. 
Ignoring the possibility of $W=0$ (perhaps we might say that $Y(0, C)=0$ : even the world's most severe plagiarist must copy/print/hand in their work and this may be thought of as 'honest' work) the student's problem is

$\max _{h, c} p(C) Z+[1-p(C)] Y(W, C)-\psi(W, C) \quad$ s.t. $C \geq 0$

Let the Kuhn-Tucker multiplier be $\lambda \geq 0$ and let partials be denoted with subscripts 1 and 2. The first-order conditions are:

$$
\begin{aligned}
& {[1-p(C)] Y_{1}=0} \\
& p^{\prime}(C)[Z-Y(.)]+[1-p(C)] Y_{2}-\psi_{2}+\lambda=0 \\
& \lambda C=0
\end{aligned}
$$

Assume that the constraint does not bind (i.e. the student cheats and $\lambda=0$ ) dividing (3.2) by (3.1) yields

$$
-\frac{\psi_{1}}{\psi_{2}}=-\frac{Y_{1}}{Y_{2}}-p^{\prime}(C)(Z-Y)
$$

Equation (3.4) says that a wedge is driven between the usual tangency between the MRTS $-\frac{Y_{1}}{Y_{2}}$ and MRT $\left(-\frac{\psi_{1}}{\psi_{2}}\right)$ by the penalty imposed for (detected) cheating. Note that the second term on the right-hand-side is positive (when incorporating the '-' in front of it). This adjustment moves the student towards higher $\mathrm{W}$ and lower $\mathrm{C}$, i.e. the penalty improves incentives for honesty.

Note that there are two ways to reduce the prospect of cheating (and, ultimately, generate a corner solution with $\mathrm{C}=0)$ : 
1. Increase the severity of penalties and monitoring (increase $p^{\prime}(C)$ and Z).

2. Modify assessment procedures to affect the relative sizes of $Y_{1}$ and $Y_{2}$, for example by using the full marking ranges (i.e. increase $Y_{1}$ ). This flattens the marks isoquant and moves the student around the production possibility frontier. Measures such as interim reports for dissertations or keeping logs of work on the development of assessed work can reduce the substitutability between $\mathrm{h}$ and $\mathrm{c}$ in the marks production function.

Figure 1 illustrates the student's optimum position and how it is affected by a penalty and the probability of detection. 


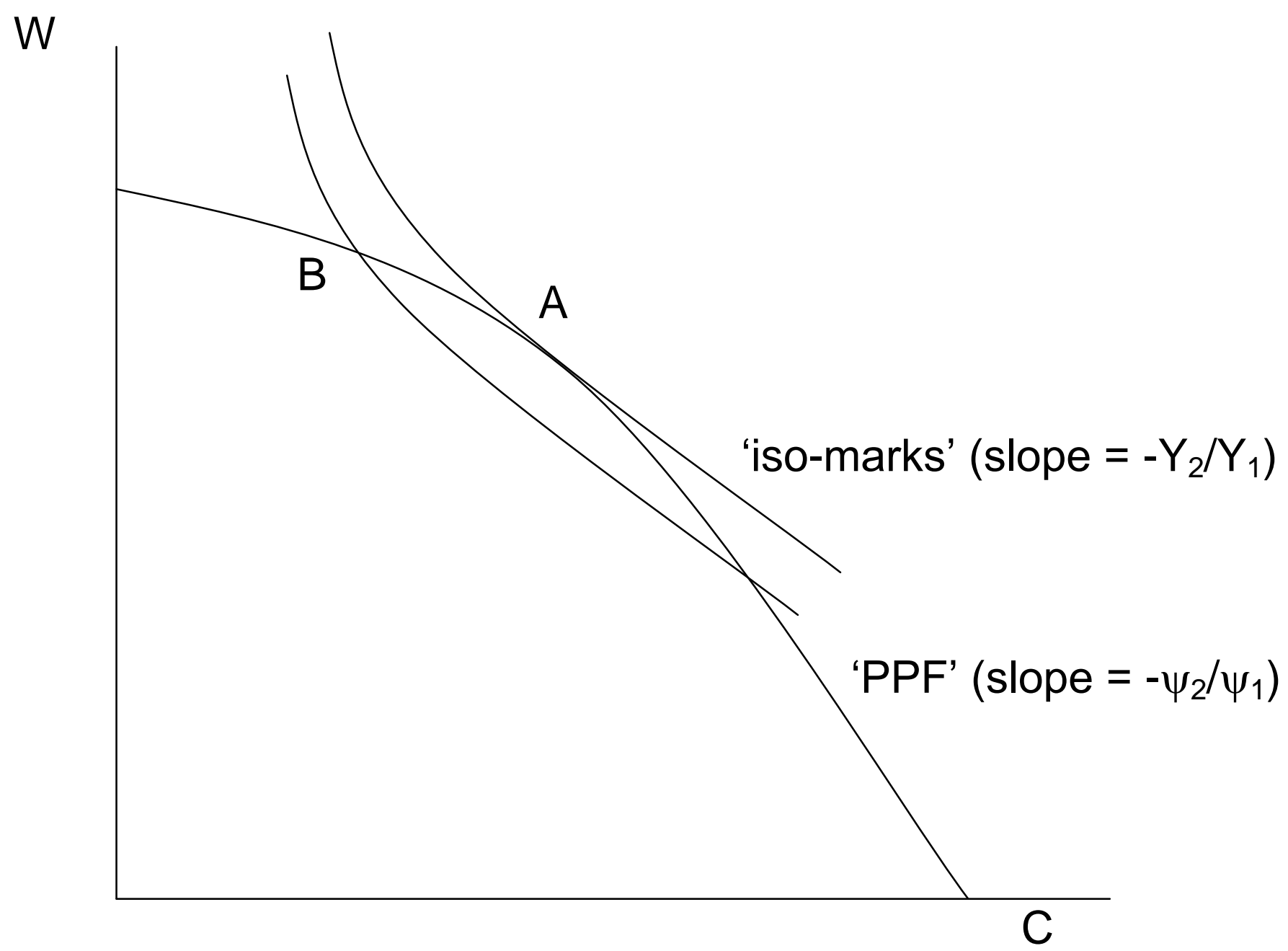

Figure 1 The trade-off between honest work and cheating

The student will move from $A$ to $B$ when

[i] $p^{\prime}(C)>0$,

[ii] $Z-Y<0$,

[iii] $Y_{1}$ increases (so the iso-marks curve flattens) 


\section{COUNTER-PLAGIARISM AND HIGHER EDUCATION POLICY}

If the theoretical models presented above are a reasonable characterisation of the decision to plagiarise then in what way should counter-plagiarism policy be shaped and how are current developments in the Higher Education sector likely to impact on the future extent of plagiarism?

While it is of course possible to alter the 'technology' of some student assessment through defensive assessment strategies and greater reliance on orthodox unseen examination papers, this does not necessarily address all the skills and knowledge domains where academics deem it appropriate to be assessed via essays and dissertation type submissions. Thus, if these types of assessments are to be retained for some significant proportion of the overall degree assessment profile, some attention needs to be directed to the costs of monitoring assessed work and increasing the probability of detecting plagiarism, and of setting a sufficiently severe punishment for those caught plagiarising.

\section{The Expected Probability of Detection}

It is clear that actual and prospective students are able to observe large or growing numbers of students taking any given degree course or course module. Arguably, merely featuring in a large cohort may contribute to the perception of some students that the likelihood of plagiarism being detected is small or falling. This can arise from some simple and plausible supposition. Consider that with a large number of essay submissions and operating within the timescales generally agreed for coursework returns, it may be considered that only a sample of these essays could realistically be subjected to detailed plagiarism detection scrutiny. Further contributing to this perception may be the accumulation of information and experience through, or within cohorts, regarding the likely distribution of plagiarism detection effort amongst academic staff. If students discerned such variations in detection effort then this could also potentially lead to strategic selection of course module options. 
Students' expectations regarding the probability of detection will also be conditioned in some part by their perceptions of their own stock of plagiarism capital. There may be observed considerable variations in the level of skill applied to producing a plagiarised output but that such skills may rapidly develop with experience and/or via demonstration. At one extreme, extremely hard-to-detect plagiarism might be characterised as exhibiting considerable time, effort, knowledge of sources and other subject-specific skills that are none too different to those required by keen hard working students not producing plagiarised coursework submissions. It may be characterised by (i) extensive use of off-line sources (especially books) as opposed to principally on-line sources, (ii) extensive re-writing with a thesaurus close to hand, and (iii) setting aside time to review the plagiarised output. More often, however, as evidenced by its easy detection in a high proportion of cases, plagiarism is simply employed as a time-saving strategy where (i) to (iii) may not feature significantly, or at all. Unaided time-saving led plagiarism will often be sloppy patchwork quilts of essay text cobbled together from a number of free web-based sources. Such attempts are easily detected using a word string in an Internet search engine such as Google. The task is rendered even easier if the text extracted from such web sources is of a high academic standard but is poorly interwoven with original text (a characteristic of many weaker students who plagiarise or for those plagiarists whose first language is not English).

However it is likely to be more efficient to make use of specialised plagiarism detectives than to expect individual academics to track down plagiarised work. If coursework is submitted in electronic form it can be checked for plagiarism against an existing database of material, both online and offline. This could be at the institutional (university) level or at a national level through the JISCPAS service. Checking for plagiarised material in this way also ensures fairness and consistency in plagiarism detection. (More informal systems of plagiarism detection at a departmental or individual academic level invite strategic behaviour on behalf of academic staff who may have reasons to be more or less vigilant in their detection and reporting of plagiarism cases. This can be analysed in a model that adopts a principal-agent framework to the management 
of plagiarism).

It seems likely that for many students who choose to plagiarise, engaging in academic work may offer less utility than other activities, or present actual disutility. Nevertheless, they require the benefits of the academic outputs in terms of assignment grades to continue in their university studies/lifestyle and to garner the benefits of graduation. It may thus be possible to erode the utility of plagiarised work by weakening the perception that once graded the plagiarised work will not be re-examined. As it stands students will be aware that academics are typically obliged to mark and return scripts within a fixed time period as part of university quality assurance procedure. Students will be aware that this renders it less likely that academic staff will have an adequate time opportunity to scrutinise in sufficient detail a large sample of the assignments being graded. Accordingly, the utility of plagiarised work could be eroded by clauses in student contracts with the university such that student records will be amended to allow for retrospective grading in any forensic auditing of coursework. Potentially this could feature the penalty of a formal withdrawal of degree title, which can present significant implications for future labour market participation and progression. Degree results could be publicly available by web searches to support employers in verifying the durability of degree results in the light of plagiarism audits.

\section{Costs and penalties of plagiarism}

As we have noted already the costs of plagiarism for a student may be separated into those that must be incurred whether or not the plagiarism is detected, and those that are only borne by students who are caught plagiarizing. The first type of costs is effectively captured in our analysis via the budget constraint, while the second enter the objective function and reduce the expected utility from plagiarising.

There are a wealth of enterprises that effectively offer plagiarism assistance to students and whose tariff structure relates to the degree of difficulty, degree level (year 1 undergraduate essays through 
to Masters dissertations and $\mathrm{PhD}$ chapters) and level of specialised human capital required to complete a particular assignment. Thus depending on the nature of the assignment fees may range from around $£ 50$ to over $£ 1500$. Such enterprises raise many further interesting questions relating to their evolution, industrial organization, and the sources of their specialised labour inputs. To what extent does it comprise other academic staff and postgraduate research students, or ex-academic staff and former postgraduate research students? There are any number of regulatory measures that may be applied to restrict the functioning and market profile of these firms, yet given their largely web-based presence, attempts to curtail trading seem likely to be doomed to failure, or even worse, be seen to encourage a move towards even more difficult to monitor hit-and-run entry by such firms around the world.

In terms of direct action, university networks could either exclude or be triggered to monitor use of proscribed plagiarism and cheat sites. Yet what of the student who uses a home PC or laptop computer? A milder yet more subtle approach to raise the expected costs of plagiarism could feature wide public reporting to the student population of in-depth reviews of the quality of cheat site outputs as part of an ongoing monitoring exercise in each subject area by legitimate university academics. Students and universities could also explicitly recognise that effective plagiarism detection is costly and that these costs need to be recovered. Student matriculation and study contracts could feature a willingness to accept fee premia in the event of plagiarism detection and potentially offer rebates after some suitable time interval to reward non-plagiarism. Where plagiarism detection costs are more explicitly recognised in student contracts there would exist the means to finance plagiarism detection more professionally within the university (a dedicated plagiarism detection unit) or by subscribing to more formal external plagiarism detection services, ideally motivated in part by performance-related fee contracts.

Some universities also operate penalties for plagiarism that instill leniency on a first offence (a yellow card/red card model). The simple model set out in this paper would suggest that such an 
approach (as discussed in Park, 2004) was folly in that it would be clearly rational to continue to plagiarise until a yellow card was achieved. Our models suggest that universities that wish to reduce the incidence of plagiarism need to have strict monitoring of coursework for plagiarism with heavy penalties for those who are caught cheating in this way.

\section{CONCLUDING REMARKS AND FUTURE EMPIRICAL RESEARCH QUESTIONS}

This brief paper sets out some simple models of the student decision to plagiarise in an attempt to provoke discussion and to help trigger an economic intervention in the debate on the nature and scale of plagiarism. It also seeks to illuminate some ways that economic thinking could influence the design of policies to combat plagiarism. In fulsome agreement with Galles et al (2003) it is argued that an economic contribution would be of considerable value in this policy arena since educationists and other policy actors may not be so inclined to direct policy attention towards (i) explicitly raising the expected probability of detection, (ii) eroding the utility of plagiarised academic work and (iii) raising the costs of plagiarism. Education academics and university 'teaching and learning professionals' seem blinkered in their apparent persistence that the level of plagiarism can be dramatically reduced or eradicated by merely ascribing a higher profile to plagiarism avoidance in learning skills modules. In truth, there will always be students who choose to plagiarise for its direct benefits and who do so with full knowledge of what plagiarism really is. Universities and other higher education stakeholders should recognise this and support attempts to address the nature and scale of the incentives to plagiarise.

To inform such work future research attention could usefully be deployed to provide an empirical examination of the costs of plagiarism to the sector and perhaps the UK economy more generally. To this end, it would also be useful to inform debate by recourse to a fuller understanding of the shadow price of academic time in plagiarism detection and the real extent of the 'overlooking' of plagiarism because of transaction costs, or an eye to pass rates (almost universally a key university 
performance indicator). Further work to support counter-plagiarism policy could also usefully explore the level and pattern of demand (by subject and type of student) of commercial services offering plagiarism and cheating support. 


\section{References}

Akerlof, George A. (1980) A Theory of Social Custom, of Which Unemployment May Be One Consequence. Quarterly Journal of Economics XCIV: 749-775.

BBC (2004) Quarter of students cheating. BBC News 20 $0^{\text {th }}$ June 2005.

http://news.bbc.co.uk/1/hi/education/3852869.stm [date accessed 3/2/05]

BBC (2005) Madonna in plagiarism case defeat BBC News $18^{\text {th }}$ November 2005 http://news.bbc.co.uk/go/pr/fr/-/1/hi/entertainment/music/4449580.stm [date accessed 19/11/2005]

Becker G. (1965) A Theory of the Allocation of Time, Economic Journal 75, 493-517.

Becker, Gary (1968) Crime and Punishment: An Economic Approach. Journal of Political Economy 76(2), 169-217.

Byrne, Ciar (2003) USA Today journalist resigns in ethics row. The Guardian (9th January 200401-13) http://media.guardian.co.uk/print/0,3858,4832590-105414,00.html [date accessed 15/01/04]

Curtis, Polly (2003) Cheating MBA student faces course expulsion. The Guardian (Thursday 24th July 2003) http://education.guardian.co.uk/print/0,3858,4719394-108229,00.html [date accessed $15 / 01 / 04]$

Enders, Walter and Hoover, Gary A. (2004) Whose Line Is It? Plagiarism in Economics, Journal of Economic Literature XLII 487-493. 
Furedi F (2004) Cheats are having a field day on campus. The Daily Telegraph (Wednesday $17^{\text {th }}$ March) 19.

Galles, Gary, Graves, Philip E., Sexton, Robert L., and Walton, Surrey M. (2003) Monitoring Costs and Tolerance Levels for Classroom Cheating, American Journal of Economics and Sociology 62(4) 713-719.

Gifford, A Jnr. (1999) Being and Time: On the Nature and Evolution of Institutions. Journal of Bioeconomics 1(1), 127-149.

Joint Information Systems Committee (JISC) (2005) Deterring, detecting and dealing with student plagiarism. http://www.jisc.ac.uk/uploaded_documents/plagFinal.pdf [date accessed $16 / 02 / 04]$

JISC Plagiarism Advisory Service (JISCPAS) (2004) Northumbria University and the Joint Information Systems Committee.

http://online.northumbria.ac.uk/faculties/art/information_studies/Imri/Jiscpas/site/jiscpas.asp [date accessed 15/01/04]

Larkham, P J and Mann, S (2002) Plagiarism and its Treatment in Higher Education. Journal of Further and Higher Education 26(4) 339-349.

McCabe, D L (2003) Ethics and Teaching: Academic Integrity. Paper presented at the 2003 Conference on Ethics in Teaching and Research, Newark, New Jersey. www.newark.rutgers.edu/gradnwk/TA\%20Conference.index.html [date accessed 15/01/04] 
Park, C (2004) Rebels without a Clause: Towards and Institutional Framework for Dealing with Plagiarism by Students. Journal of Further and Higher Education. 28(3) 291-306.

Rangwala, Glen (2003) British Intelligence Iraq Dossier Relies on Recycled Academic Articles. http://www.globalpolicy.org/security/issues/iraq/attack/2003/0205plagiarism.htm [date accessed 3/02/05]

Sharpe, Tom (1974) Porterhouse Blue London, Secker \& Warburg.

Stevens, P and Weale, M (2004) Lazy Students? A Study of Student Time Use. National Institute of Economic and Social Research. http://www.niesr.ac.uk/PUBS/DPS/dp233.PDF [date accessed 3/02/05]

Szabo, A and Underwood, J (2003) Cybercheats: Is Information and Communications Technology Fuelling Academic Dishonesty? Active Learning in Higher Education 5(2) 180-199.

Turnitin.com (2005) http://www.turnitin.com/static/tour/tour_master.html [date accessed 3/02/05]

Case referred to:

Clark v. University of Lincolnshire and Humberside (2000), UK Court of Appeal (Civil Division) $19^{\text {th }}$ April 2000. Reference: [2000]3 All ER 752. 